ASTHMA

\title{
Mast cell migration to Th2 stimulated airway smooth muscle from asthmatics
}

\author{
A Sutcliffe, D Kaur, S Page, L Woodman, C L Armour, M Baraket, P Bradding, \\ J M Hughes, C E Brightling
}

See end of article for authors' affiliations .....................

Correspondence to: Dr C E Brightling, University Hospitals of Leicester, Groby Road Leicester LE3 9QP, UK ceb17@le.ac.uk

Received 5December 2005 Accepted 21 March 2006 Published Online First 6 April 2006
Background: Mast cell microlocalisation within the airway smooth muscle (ASM) bundle is an important determinant of the asthmatic phenotype. We hypothesised that mast cells migrate towards ASM in response to ASM derived chemokines.

Methods: Primary ASM cultures from subjects with and without asthma were stimulated with interleukin (IL)- $1 \beta$, IL-4, and IL-13 alone and in combination. Mast cell chemotaxis towards these ASM supernatants was investigated, and the chemotaxins mediating migration by using specific blocking antibodies for stem cell factor (SCF) and the chemokine receptors CCR3, CXCR1, 3 and 4 as well as the Gi inhibitor pertussis toxin and the tyrosine kinase inhibitor genistein were defined. The concentrations of CCL11, CXCL8, CXCL10, TGF- $\beta$, and SCF in the supernatants were measured and the effect of non-asthmatic ASM supernatants on the mast cell chemotactic activity of asthmatic ASM was examined.

Results: Human lung mast cells and HMC-1 cells migrated towards Th2 stimulated ASM from asthmatics but not non-asthmatics. Mast cell migration was mediated through the combined activation of CCR3 and CXCR1. CCL1 1 and CXCL8 expression by ASM increased markedly after stimulation, but was similar in those with and without asthma. ASM supernatants from non-asthmatics inhibited mast cell migration towards the asthmatic ASM supernatant.

Conclusion: Th2 stimulated ASM from asthmatics is chemotactic for mast cells. Non-asthmatic ASM releases a mediator or mediators that inhibit mast cell migration towards stimulated asthmatic ASM. Specifically targeting mast cell migration into the ASM bundle may provide a novel treatment for asthma.
A sthma is a common disease and remains a significant cause of morbidity and mortality worldwide. ${ }^{1}$ It is characterised by the presence of variable airflow obstruction, airway hyperresponsiveness, eosinophilic airway inflammation, T helper 2 (Th2) cytokine expression, and increased deposition of extracellular matrix beneath the basement membrane. ${ }^{23}$ We have recently shown that, in addition to these features, the airway smooth muscle (ASM) in asthma is infiltrated by mast cells. In contrast, mast cells within the ASM bundle was not a feature of non-asthmatic eosinophilic bronchitis or healthy controls, suggesting that this is a major determinant of the asthmatic phenotype. ${ }^{4-6}$

It is likely that mast cells migrate towards the ASM bundle in asthma under the influence of ASM derived chemotaxins. Stem cell factor (SCF) is produced by human ASM and is chemotactic for mast cells, ${ }^{78}$ as well as being essential for their differentiation, maturation, proliferation and survival (reviewed by Page et $a l^{9}$ ). A role for SCF in the microlocalisation of mast cells to the ASM in asthma has therefore been proposed and needs further investigation. Alternatively, mast cell migration may be mediated by chemokines. We have recently shown that the chemokine receptors most commonly expressed by human lung mast cells are CCR3, CXCR1, CXCR3 and CXCR4. ${ }^{10}$ Supernatants derived from ASM from asthmatics stimulated with Thl cytokines in vitro had greater mast cell chemotactic activity than ASM from normal controls. ${ }^{11}$ Interestingly, the ASM from these asthmatics preferentially released the CXCR3 ligand CXCL10 compared with ASM from non-asthmatics and CXCR3 blockade inhibited the mast cell chemotactic activity. The CXCL10/ CXCR3 axis is therefore important in the migration of mast cells towards ASM in asthma. Although CXCL10 expression is upregulated in stable asthma ${ }^{12}$ and after allergen challenge, ${ }^{13-15}$ there is a considerable body of evidence supporting the view that asthma is predominately a Th2 mediated disease. ${ }^{16}$

In asthma there is increased Th2 cytokine expression in bronchoalveolar lavage (BAL) fluid, ${ }^{17}$ sputum, ${ }^{18}$ and bronchial biopsy specimens ${ }^{17}{ }^{19}$ in stable disease and after allergen challenge $^{20}$ and, in addition, the mast cells in the ASM bundle in asthma express IL-4 and IL-13 on their surface. ${ }^{21}$ Thus, whether ASM stimulated with Th2 cytokines is also chemotactic for human mast cells needs to be examined. In this study we have tested our hypothesis that human lung mast cells (HLMC) and HMC-1 cells migrate in response to chemotaxins secreted by ASM from subjects with asthma, but not non-asthmatics, stimulated by Th2 cytokines.

\section{METHODS}

Subjects

Subjects were recruited from Sydney, Australia with two additional asthmatics recruited from Leicester, UK. Those with asthma gave an appropriate history and had objective evidence of variable airflow obstruction as indicated by one or more of the following: (1) airway hyperresponsiveness (methacholine concentration required to cause a $20 \%$ fall in forced expiratory volume in 1 second $\left(\mathrm{PC}_{20} \mathrm{FEV}_{1}\right)<8 \mathrm{mg} / \mathrm{ml}$ or maximum cumulative mannitol dose required to cause a $15 \%$ fall in $\left.\mathrm{FEV}_{1}\left(\mathrm{PD}_{15} \quad \mathrm{FEV}_{1}\right)<635 \mathrm{mg} / \mathrm{ml}\right)$; (2) $>15 \%$ improvement in $\mathrm{FEV}_{1} 10$ minutes after $200 \mu \mathrm{g}$ inhaled salbutamol; or (3) peak expiratory flow (PEF) $\quad(>20 \%$

Abbreviations: $A S M$, airway smooth muscle; $\mathrm{FEV}_{1}$, forced expiratory volume in 1 second; HLMC, human lung mast cell; IL, interleukin; IFN- $\gamma_{\text {, }}$ interferon $\gamma$; SCF, stem cell factor; TGF $\beta$, transforming growth factor $\beta$; Th2, T helper 2 
maximum within day amplitude from twice daily PEF measurements over 14 days). Subjects with asthma underwent bronchoscopy. Non-asthmatic subjects were undergoing lung resection for either lung transplantation or carcinoma. The study was approved by the Leicestershire and Sydney Central Area Health Service and University of Sydney Human Ethics Committees and all patients gave their written informed consent.

\section{Airway smooth muscle isolation and culture}

From bronchial biopsy specimens or resected bronchial tissue, pure ASM bundles were dissected free of surrounding tissue. In the non-asthmatics the ASM was derived from similar airway divisions to the bronchial biopsies. The small muscle bundles were cultured in DMEM supplemented with $10 \%$ FBS, $4 \mathrm{mM}$ L-glutamine, $100 \mathrm{U} / \mathrm{ml}$ penicillin, $100 \mu \mathrm{g} / \mathrm{ml}$ streptomycin, and $0.25 \mu \mathrm{g} / \mathrm{ml}$ amphotericin. ASM cell characteristics were determined by immunofluorescence and light microscopy with $\alpha$-smooth muscle actin-FITC direct conjugate and calponin and myosin indirectly conjugated with FITC (Sigma, Gillingham, Dorset, UK).

\section{Mast cell isolation and culture}

HLMC from normal lung obtained at surgery for carcinoma at Leicester, UK (seven donors) were isolated by immunomagnetic affinity purification using the Dynal Cellection kit (Dynal, Oslo, Norway) as previously described. ${ }^{22}$. A typical lung sample provided a yield of $0.1-0.5 \times 10^{6} \mathrm{HLMC} / \mathrm{g}$ of lung of $>98 \%$ purity. Cells were cultured in DMEM, $10 \%$ fetal bovine serum (FBS) supplemented with SCF ( $100 \mathrm{ng} / \mathrm{ml})$, IL$10(10 \mathrm{ng} / \mathrm{ml})$, and IL-6 $(50 \mathrm{ng} / \mathrm{ml})$ (R\&D Systems, Abingdon, Oxfordshire, UK).

\section{HMC- 1 cells}

The HMC-1 cell line was a gift from Dr J Butterfield (Mayo Clinic, Rochester, MN, USA). HMC-1 cells were maintained in Iscove's modified DMEM as described previously. ${ }^{23}$

\section{ASM stimulation}

ASM cells from nine asthmatic and six non-asthmatic subjects were plated into 6 -well plates $\left(9.6 \times 10^{4}\right.$ cells in $2 \mathrm{ml} \mathrm{DMEM}$ and $10 \% \mathrm{FBS}$ ), grown for 1 week, then growth was arrested for 48 hours with serum deprived medium and either left unstimulated or stimulated with IL-1 $\beta$ and/or Th2 cytokines as follows: (i) IL- $1 \beta$, (ii) IL-4, (iii) IL-13, (iv) IL-4 and IL-13, and (v) IL-1 $\beta$, IL-4 and IL-13 (10 ng/ml of each; R\&D Systems, Abingdon, UK) for 24 hours. Using the same protocol, further ASM from five asthmatics and six nonasthmatics were stimulated with Thl cytokines IL-1 $\beta$, TNF $\alpha$ and IFN- $\gamma(10 \mathrm{ng} / \mathrm{ml}$ each cytokine in combination; R\&D Systems). The cytokine concentrations were chosen to reflect the maximal response as identified in previous reports. ${ }^{24}$ Supernatants were collected and stored at $-80^{\circ} \mathrm{C}$ and cell counts were derived for the cells in each well. Experiments were performed using ASM cells from passage 3-7 and the passage number was not different between ASM from subjects with or without asthma.

Insufficient supernatants were available to study the role of SCF in mast cell migration to Th2 stimulated ASM supernatants. Thus, additional ASM supernatants from seven asthmatics and eight non-asthmatics where non-confluent cells had been left unstimulated or stimulated with IL-4 and IL-13 $(20 \mathrm{ng} / \mathrm{ml})$ for 48 hours after serum deprivation for 24 hours were used.

\section{Chemotaxis assays}

Chemotaxis assays were performed using Transwells with fibronectin coated inserts with a pore size of $8 \mu \mathrm{m}$ (BD, Oxford, UK) as previously described.$^{10}$ We placed $1 \times 10^{5}$ HLMC or $2 \times 10^{5}$ HMC- 1 cells in $100 \mu \mathrm{l}$ culture medium supplemented with $2 \%$ FCS into the top well, and $450 \mu \mathrm{l}$ of supernatant from stimulated ASM or appropriate negative control in the bottom well. Checkerboard analysis was used to distinguish chemotactic from chemokinetic activity. Mast cells were preincubated with pertussis toxin $(0.5 \mu \mathrm{g} / \mathrm{ml})$ for 1 hour and 16 hours and with the tyrosine kinase inhibitor genistein $(0.5 \mu \mathrm{g} / \mathrm{ml})$ for 1 hour before the chemotaxis assays to assess the effect of these inhibitors on migration as previously described. ${ }^{24}$ Similarly, to assess the relative importance of individual chemokine receptors, we preincubated the cells with receptor blocking antibodies CCR3, CXCR1, CXCR3 and CXCR4 (R\&D Systems) alone or in combination or isotype controls for 1 hour. After preincubation with inhibitors, the cells were washed and recounted to ensure that the number of cells added to the top chamber of the chemotaxis wells was consistent across conditions. The role of SCF was examined using the chemotaxis assay outlined above with ASM supernatants or recombinant SCF $(50 \mathrm{ng} / \mathrm{ml})$ in the bottom well preincubated with SCF neutralising antibody or an isotype control for 0.5 hours (R\&D Systems).

We considered that ASM supernatants from non-asthmatics might affect the chemotactic activity of asthmatic ASM supernatants. To investigate this possibility we assessed mast cell chemotaxis towards Th1 and Th2 stimulated ASM supernatants from asthmatics after titration with media alone or with the corresponding Th1 or Th2 stimulated nonasthmatic ASM supernatants using the chemotaxis assay described above. In these chemotaxis assays the final concentration of the asthmatic ASM supernatant as a proportion of neat supernatant was $12.5-75 \%$.

\section{Concentration of mediators in conditioned ASM supernatants}

The concentrations of several putative mast cell chemotaxins were measured in the Th2 stimulated ASM supernatants by commercial ELISA: CCL11 (BD), CXCL8 (BD), CXCL10 (BD), SCF (R\&D), and TGF- $\beta$ (R\&D). In addition, we measured using ELISA, in Thl and Th2 stimulated ASM supernatants, $\mathrm{PGE}_{2}$ (Cayman Chemical, Ann Arbor, MI, USA) and IFN- $\beta$ $(R \& D)$ as we considered that these mediators may play a role in modulating the migration of mast cells towards ASM supernatants. The concentration of mediators was corrected for cell number. The limits of detection were as follows: CCL11 (6.25 pg/ml), CXCL8 (3.1 pg/ml), CXCL10 (31.5 pg/ $\mathrm{ml}), \operatorname{SCF}(15.63 \mathrm{pg} / \mathrm{ml}), \mathrm{TGF}-\beta(31.25 \mathrm{pg} / \mathrm{ml}), \mathrm{PGE}_{2}(15 \mathrm{pg} /$ $\mathrm{ml})$, and IFN- $\beta(250 \mathrm{pg} / \mathrm{ml})$.

\section{Statistical analysis}

HLMC and HMC-1 migration was expressed as the geometric mean (SE) fold difference in migration compared with control and the effect of blocking antibodies and inhibitors was expressed as mean (SE) \% inhibition. Chemokine concentrations for CCL11 and CXCL8 were log normally distributed and were described as the geometric mean $(\log S E)$; the other chemotaxins or mediators were described as median (interquartile range). The mast cell chemotactic index for ASM stimulated with each condition was assessed by $t$ test. Comparison between mast cell migration towards asthmatic versus non-asthmatic ASM stimulated with different conditions were analysed by ANOVA across conditions and by unpaired $t$ tests for each condition separately. A value of $\mathrm{p}<0.05$ was taken as statistically significant.

\section{RESULTS \\ Chemotactic activity for HMC-1 and HLMC by asthmatic ASM}

Supernatants of ASM cells from asthmatic subjects $(n=7)$ were markedly more chemotactic for HMC-1 cells than those 

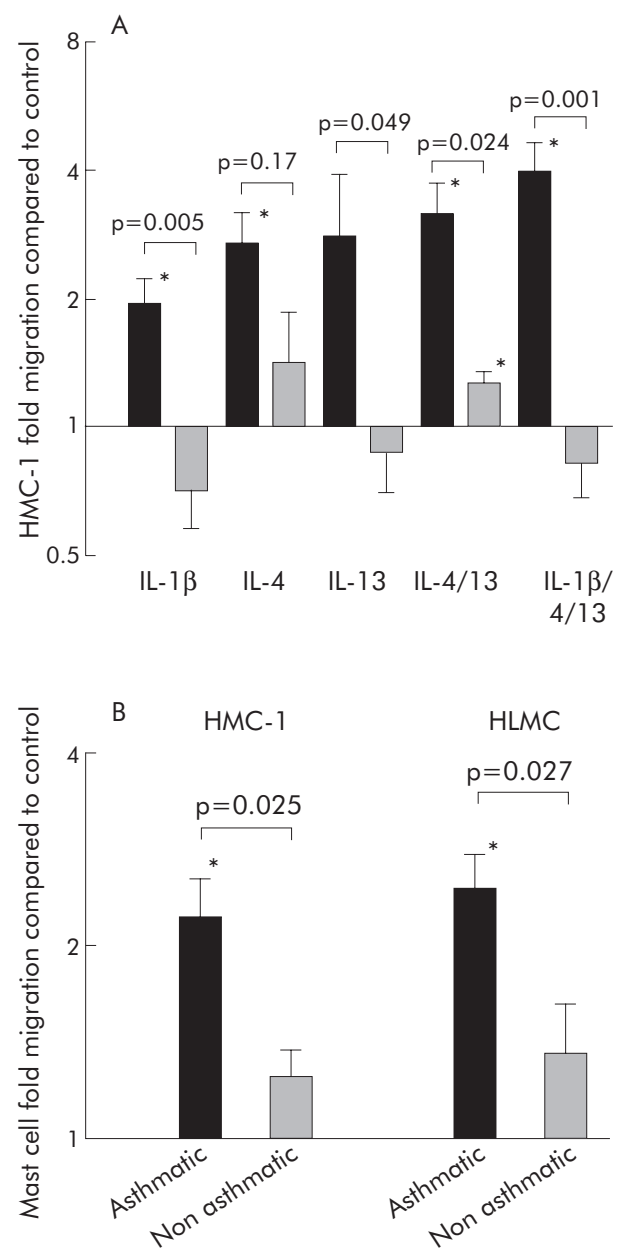

Figure 1 (A) Mean (SE) HMC-1 migration towards asthmatic and nonasthmatic ASM stimulated with IL-1 $\beta$, IL- 4 and IL-13 alone or in combination. Solid bars represent asthmatic ASM, hatched bars respresent non-asthmatic ASM. (B) Mean (SE) HMC-1 and HLMC migration towards asthmatic and non-asthmatic ASM stimulated with IL$1 \beta$, IL-4 and IL-13 in combination after supernatants were corrected for cell number. Stated $p$ values are for comparisons of mast cell migration towards asthmatic $v$ non-asthmatic ASM; ${ }^{*} p<0.05$ for mast cell migration towards ASM conditioned media compared with contro media. $p$ values on the figure represent comparisons between asthmatics and non-asthmatics.

from non-asthmatic subjects $(\mathrm{n}=5)$ when the ASM cells were activated with IL- $1 \beta$ or IL- 13 alone, IL- 4 and IL-13 in combination, or with IL- $1 \beta$, IL-4 and IL- 13 in combination (fig 1A). The cell number from the asthmatic ASM cultures (3.2 (0.4) $\times 10^{5}$ cells/well) was increased compared with the non-asthmatic ASM cultures (1.1 (0.3) × $10^{5}$ cells/well; $\mathrm{p}=0.001)$, so migration assays were performed towards the IL- $1 \beta$, IL- 4 and IL-13 stimulated ASM cell supernatants with the supernatant diluted to correct for the difference in cell number. Even after this correction the supernatants from the asthmatic ASM remained chemotactic for mast cells (2.2-fold compared with control media; $\mathrm{p}=0.008$ ) and was increased compared with those from non-asthmatics (1.3-fold $v$ 2.2fold; $p=0.025$; fig $1 \mathrm{~B}$ ). HMC-1 migration towards ASM stimulated with IL-1 $\beta$, IL-4 and IL-13 in combination $(n=4)$ was not inhibited by CCR3, CXCR1, CXCR3 or CXCR4 blocking antibodies alone but was in combination (94 (6)\% inhibition compared with isotype control; $\mathrm{p}<0.001)$. Isotype controls did not affect HMC-1 migration (data not shown). HMC-1 migration towards triple stimulated ASM was also inhibited by genistein and pertussis toxin (fig 2A).
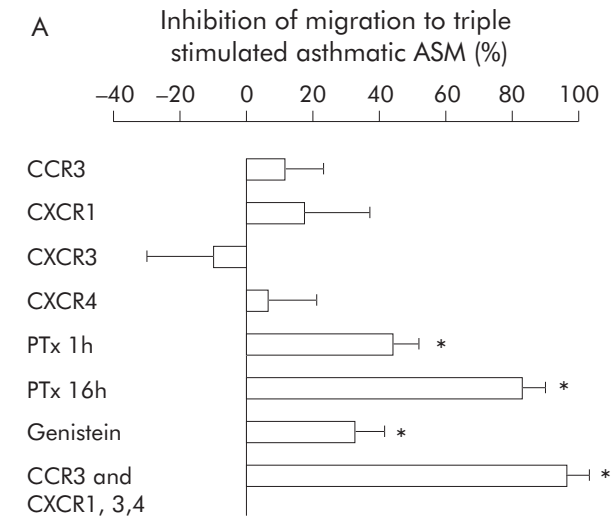

B

Inhibition of migration to triple stimulated asthmatic ASM (\%)

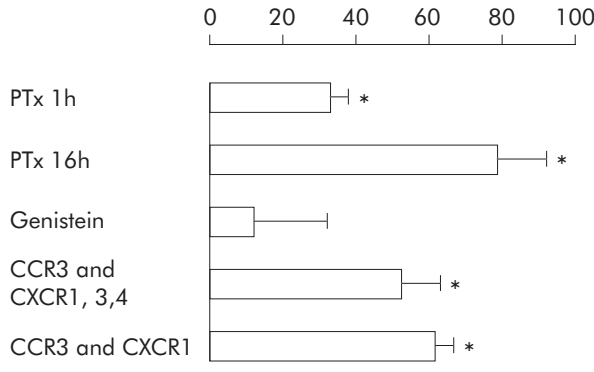

Figure 2 Mean (SE) \% inhibition of (A) HMC-1 and (B) HLMC migration towards asthmatic ASM stimulated with IL-1 $\beta$, IL-4 and IL-13 in combination after preincubation of mast cells with chemokine receptor blocking antibodies, pertussis toxin (PTx), or genistein $\left({ }^{*} p<0.05\right)$.

Similarly, IL-1 $\beta$, IL-4 and IL-13 stimulated ASM supernatants from asthmatics $(n=6)$, after correction for cell number, were chemotactic for HLMC (2.4-fold $v$ control media; $p=0.002$ ), but not ASM supernatant from nonasthmatics $(\mathrm{n}=7 ; 1.4$-fold; $\mathrm{p}=0.2)$. There was a significant difference between HLMC migration towards asthmatic compared with non-asthmatic ASM supernatant $(p=0.03$; fig 1B). HLMC migration towards asthmatic ASM stimulated with IL-1 $\beta$, IL-4 and IL-13 in combination $(n=4)$ was inhibited by pertussis toxin; CCR3, CXCR1, CXCR3 and CXCR4 blocking antibodies in combination (51 (11)\% inhibition; $\mathrm{p}=0.043)$; and CCR3 and CXCR1 blocking antibodies in combination (59 (5)\% inhibition; $\mathrm{p}=0.006$ ) compared with media alone with or without isotype control, but not genistein (fig 2B).

HMC-1 chemotaxis to the asthmatic and non-asthmatic ASM supernatants was not affected by SCF neutralising antibody (data not shown), although HMC-1 chemotaxis to SCF $(50 \mathrm{ng} / \mathrm{ml})$ was inhibited by $97.6(0.9) \% \quad(\mathrm{p}<0.001$, $\mathrm{n}=3$ ).

Checkerboard analysis confirmed that HMC-1 and HLMC migration towards Th2 stimulated asthmatic ASM supernatants was due to chemotaxis rather than chemokinesis. IL$1 \beta$, IL- 4 and IL-13 in the medium at concentrations used to stimulate the ASM did not induce HMC-1 or HLMC migration (data not shown).

\section{Chemokine expression by ASM}

The concentration of CCLll was increased in the ASM supernatants after stimulation with IL-13 alone or in combination with IL-4 and IL-1 $\beta$ (fig 3A). However, there was no difference in CCLIl concentration between ASM from asthmatic $(n=7)$ or non-asthmatic subjects $(n=5)$ 

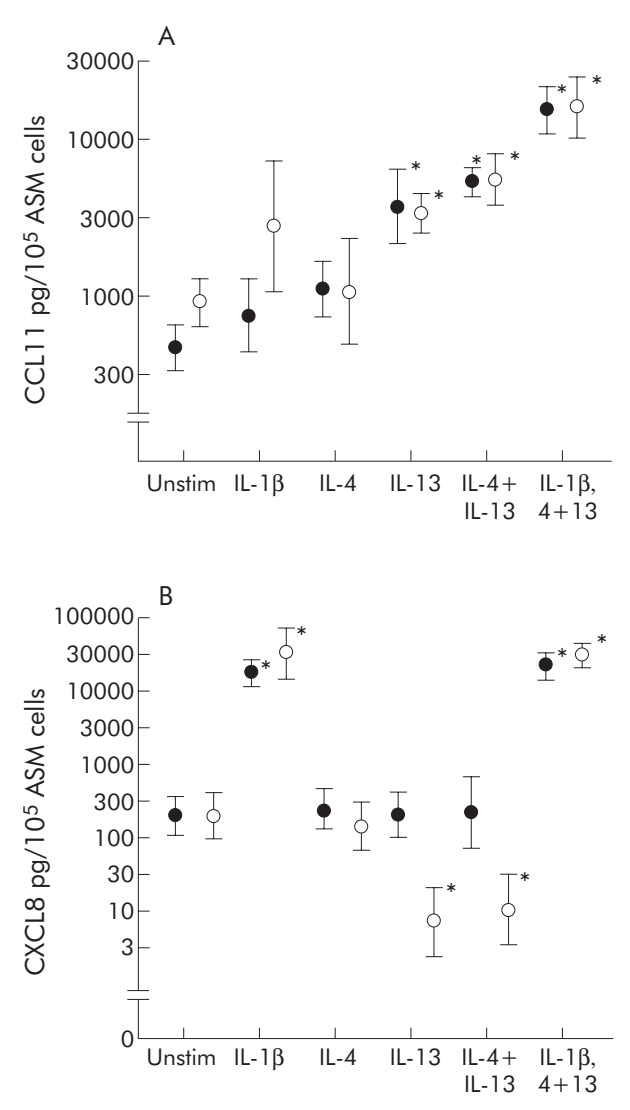

Figure 3 Geometric mean (SE) concentration of (A) CCL1 1 and (B) CXCL8 in the supernatants from stimulated ASM from asthmatics (closed symbols) and non-asthmatics (open symbols). ${ }^{*} p<0.05$.

before or after stimulation once the supernatants were corrected for cell number. CXCL8 concentration was increased in the supernatants stimulated with IL- $1 \beta$ alone or in combination with IL-4 and IL-13. The CXCL8 concentration did not increase with IL-4 or IL-13 stimulation alone or in combination. Indeed, the CXCL8 concentration decreased after stimulation with IL-13 alone or in combination with IL-4 in the non-asthmatic but not in the asthmatic ASM supernatants (fig 3B).

In the ASM supernatants stimulated with IL- $1 \beta$, IL-4 and IL-13, the concentrations of CXCL10 and TGF $\beta$ were low and not increased in those from asthmatic (52 (16-198) and 20 $(2-27) \mathrm{pg} / 10^{5}$ cells) compared with non-asthmatic subjects (258 (72-506) and $36(0-84) \mathrm{pg} / 10^{5}$ cells). Likewise, similar amounts of soluble SCF were detected in the unstimulated supernatants of ASM cells from seven asthmatic subjects (87.6 (63-151) pg/10 cells) and eight non-asthmatic subjects (128 (84-136) pg/10 $0^{5}$ cells), and stimulation with the Th2 cytokines IL-4 and IL-13 did not alter their SCF release (data not shown).

\section{Asthmatic ASM chemotactic activity attenuated by non-asthmatic ASM}

Supernatants of ASM cells from three asthmatic subjects stimulated with Th1 (IL-1 $\beta$, TNF $\alpha$ and IFN- $\gamma$ ) or Th2 (IL-1 $\beta$, IL-4 and IL-13) cytokines were markedly more chemotactic for HMC-1 than those from three non-asthmatic subjects (fig 4). This chemotactic activity of asthmatic ASM was attenuated by titration with media alone, but inhibition of chemotaxis was more marked by titration with nonasthmatic ASM supernatants (fig 4).
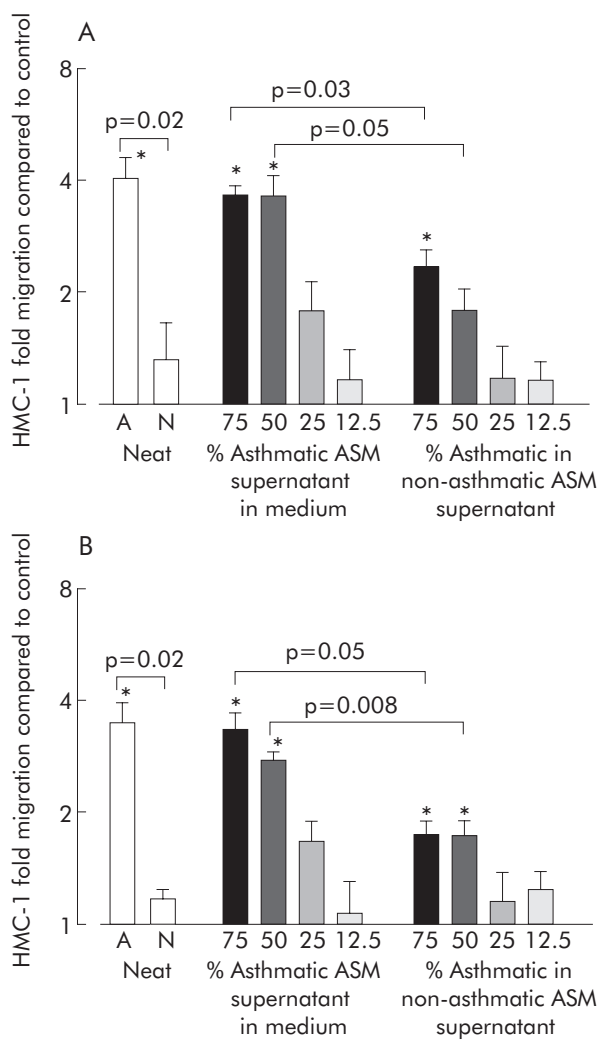

Figure 4 Mean (SE) HMC-1 migration towards neat (A) Th1 stimulated and (B) IL-1 $\beta$, IL-4 and IL-13 stimulated ASM supernatants from three asthmatic and three non-asthmatic donors, and towards stimulated asthmatic ASM supernatants after titration with media alone or with nonasthmatic stimulated ASM supernatants. Final concentration of asthmatic ASM supernatant was $12.5-75 \%$ of neat supernatant. ${ }^{*} p<0.05$ HMC-1 migration towards supernatant compared with control.

$\mathrm{PGE}_{2}$ concentrations in ASM supernatants stimulated with IL-1 $\beta$, IL- 4 and IL-13 (Th2 stimulated) or IL-1 $\beta$, TNF $\alpha$ and IFN- $\gamma$ (Thl stimulated) were not significantly different in subjects with asthma ( $1(4-37) \mathrm{ng} / 10^{5}$ cells and 17 (13$22) \mathrm{ng} / 10^{5}$ cells) and non-asthmatic subjects (3 (2-30) ng/ $10^{5}$ cells and $17(15-20) \mathrm{ng} / 10^{5}$ cells respectively; $\left.\mathrm{p}>0.05\right)$. IFN- $\beta$ was undetectable in all of the Thl and Th2 stimulated samples.

\section{DISCUSSION}

We have made several new and important observations. Supernatants from Th2 stimulated ASM from subjects with asthma, but not non-asthmatics, induced HLMC and HMC-1 migration. This was mediated predominantly through activation of CCR3 and CXCRl, even though ligands for these receptors, CCL11 and CXCL8 were not released preferentially by asthmatic ex vivo ASM cells compared with those from non-asthmatic subjects. Importantly, ASM supernatants from non-asthmatics inhibited the mast cell chemotactic activity of Th1 and Th2 stimulated asthmatic ASM. These observations suggest that ASM from non-asthmatics release an inhibitory factor or factors that attenuate chemokine mediated migration of mast cells towards ASM.

In asthma the ASM bundle is infiltrated by mast cells. ${ }^{4}$ This is not a feature of eosinophilic bronchitis or normal controls, suggesting that mast cell-ASM interactions may be fundamental in the development of the asthma phenotype. It is therefore likely that mast cells migrate to ASM under the influence of chemotaxins released by ASM. Indeed, we found that supernatants from Th2 stimulated ASM from 
asthmatics, but not non-asthmatic subjects, were chemotactic for HLMC and HMC-1 cells. Similarly, we confirmed that Thl stimulated asthmatic ASM had increased mast cell chemotactic activity compared with non-asthmatic ASM. ${ }^{11}$ The lack of chemotactic activity in the Th2 stimulated ASM supernatants from the non-asthmatic subjects is consistent with the paucity of mast cells in the healthy ASM in bronchial biopsies. Blocking the chemokine receptors most commonly expressed by HLMC (CCR3, CXCR1, CXCR3 and CXCR4) alone had little effect on mast cell migration towards the Th2 stimulated asthmatic ASM but, importantly, migration was inhibited markedly by Gi inhibitor pertussis toxin and by blocking CCR3 in combination with CXCR1. HMC-1 migration, but not HLMC migration, was inhibited partly by genistein, a tyrosine kinase inhibitor, which suggests that chemotaxins that activate this pathway such as TGF- $\beta$ are unlikely to play a significant role in mast cell migration towards Th2 stimulated ASM supernatants. Taken together, our findings therefore suggest that activation of CCR3 and CXCRl is the dominant mechanism mediating mast cell chemotaxis towards Th2 stimulated asthmatic ASM.

In this study we found, as reported by Hirst et al, ${ }^{25}$ that ASM released increased concentrations of the CCR3 ligand CCL11 after Th2 stimulation and the CXCR1 ligand CXCL8 after stimulation with IL- $1 \beta$. Intriguingly, the concentrations of these chemokines were not different between asthmatic and non-asthmatic subjects. The concentrations of these chemokines in the ASM supernatants cannot therefore explain the differential migration towards Th2 stimulated asthmatic and non-asthmatic ASM supernatant. One possible explanation for this apparent anomaly is that other CCR3 and/or CXCRI chemokines are released preferentially by asthmatic ASM. However, recombinant CCL11 and CXCL8 at similar concentrations to those released by Th2 stimulated non-asthmatic ASM are chemotactic for mast cells. ${ }^{102627}$ Therefore, an alternative explanation for the different mast cell chemotactic activity between asthmatic and non-asthmatic ASM is that a mediator released by non-asthmatic ASM inhibits mast cell migration. In support of this view we found that the mast cell chemotactic activity of Th2 stimulated ASM was inhibited by titration with nonasthmatic ASM more markedly than titration with media alone. The inhibitory capacity of non-asthmatic ASM supernatant was not reserved to ASM stimulated with Th2 cytokines. Indeed, we found that mast cell migration towards Thl stimulated asthmatic ASM was likewise inhibited by non-asthmatic ASM. We have considered a number of possible explanations for this phenomenon. The CXCR3 ligands are natural antagonists for $\mathrm{CCR}^{28}$ and therefore have the capacity to inhibit CCR3 mediated migration in the Th2 stimulated asthmatic ASM. However, the CXCL10 concentration was low and was not increased in the Th2 stimulated asthmatic ASM, so it is unlikely to have influenced mast cell migration. $\mathrm{PGE}_{2}$ secretion by asthmatic ASM in response to serum is reduced, ${ }^{29}$ but we found it was not different between asthmatics and non-asthmatics after Th1 or Th2 stimulation, in keeping with earlier findings. ${ }^{30}$ This suggests that this mediator is unlikely to be responsible for the differential mast cell migration towards asthmatic and non-asthmatic ASM. IFN- $\beta$ has been implicated in modifying chemokine release by ASM via an autocrine mechanism, ${ }^{31}$ but we were unable to detect IFN- $\beta$ in samples from asthmatics or non-asthmatics stimulated with Thl or Th2 cytokines, suggesting that this mediator is also unlikely to affect mast cell migration towards ASM supernatants. In addition, the non-asthmatic ASM was derived from airways of a similar division to bronchial biopsies and the ASM passage number did not differ between asthmatic and nonasthmatic subjects, which suggests that these technical issues cannot explain our findings. The mechanism by which nonasthmatic ASM inhibits mast cell migration therefore remains unexplained and needs to be further examined.

In this study mast cell migration towards Th2 stimulated asthmatic ASM was mediated by activation of CCR3 and CXCRl in combination. However, it is likely that mast cell migration towards the ASM in asthma is under the control of several chemotaxins, and the relative importance of each of these varies depending upon the inflammatory environment within the individual asthmatic. In an earlier study we found that mast cell migration towards the ASM bundle in asthma was mediated via CXCL10 activation of CXCR3. ${ }^{11}$ ASM bundles in bronchial biopsies from asthmatics expressed CXCL10 constitutively and, following Thl stimulation, asthmatic ASM preferentially released CXCL10. ASM activated by tryptase induced mast cell chemotaxis after the production of TGF- $\beta_{1}$ and SCF. ${ }^{7}$ Th2 stimulation did not increase CXCL10, TGF- $\beta$ and SCF expression and SCF was not involved in ASM induced mast cell chemotaxis, supporting the view that the type of inflammatory stimulus determines the dominant mast cell chemotaxin released by ASM. Further work is required to identify the important factors that may be involved in mast cell migration towards ASM stimulated by mast cells themselves. It also remains a possibility that it is mast cell precursors that are recruited by the ASM rather than mature airway cells. Interestingly, the expression of CCR3 on human bone marrow derived mast cells is similar to mature lung mast cells, ${ }^{10}$ suggesting that this chemokine receptor may be particularly important in the recruitment of progenitors to tissue. ${ }^{32}$

In summary, our findings show that ASM from asthmatics, when stimulated with Th2 cytokines, is chemotactic for mast cells predominantly mediated by activation of mast cell CCR3 and CXCR1. Non-asthmatic ASM releases a mediator or mediators that inhibit mast cell migration towards both Thl and Th2 stimulated asthmatic ASM. Specifically targeting mast cell migration into ASM bundles may provide a novel effective treatment for asthma.

\section{ACKNOWLEDGEMENTS}

The authors thank the theatre and pathology staff of the Sydney metropolitan hospitals and University Hospitals of Leicester for the supply of human lung tissue and the collaborative effort of the cardiopulmonary transplant team at St Vincent's Hospital, Sydney. They also thank Mrs D Parker for technical support.

\section{Authors' affiliations}

A Sutcliffe, D Kaur, L Woodman, P Bradding, C E Brightling, Institute for Lung Health, Department of Infection, Inflammation and Immunity, University of Leicester, Leicester, UK

S Page, C L Armour, M Baraket, J M Hughes, Respiratory Research Group, Faculty of Pharmacy and Department of Pharmacology, University of Sydney, Australia

Supported by Asthma UK, DoH UK Clinician Scientist Scheme, NHMRC Australia.

Competing interests: none.

\section{REFERENCES}

1 Green RH, Brightling CE, Pavord ID, et al. Management of asthma in adults: current therapy and future directions. Postgrad Med J 2003;79:259-67

2 Wardlaw AJ, Brightling C, Green R, et al. Eosinophils in asthma and other allergic diseases. Br Med Bull 2000;56:985-1003.

3 Kay AB. Pathology of mild, severe, and fatal asthma. Am J Respir Crit Care Med 1996; 154:S66-9.

4 Brightling CE, Bradding P, Symon FA, et al. Mast-cell infiltration of airway smooth muscle in asthma. N Engl J Med 2002;346:1699-705.

5 Robinson DS. The role of the mast cell in asthma: induction of airway hyperresponsiveness by interaction with smooth muscle? J Allergy Clin Immunol 2004;114:58-65. 
6 Brightling CE, Symon FA, Birring SS, et al. Comparison of airway immunopathology of eosinophilic bronchitis and asthma. Thorax 2003;58:528-32

7 Berger P, Girodet PO, Begueret H, et al. Tryptase-stimulated human airway smooth muscle cells induce cytokine synthesis and mast cell chemotaxis. FASEB J 2003;17:2139-41.

8 Kassel O, Schmidlin F, Duvernelle C, et al. Human bronchial smooth muscle cells in culture produce stem cell factor. Eur Respir J 1999;13:951-4.

9 Page S, Ammit AJ, Black JL, et al. Human mast cell and airway smooth muscle cell interactions: implications for asthma. Am J Physiol Lung Cell Mol Physiol 2001;281:L1313-23.

10 Brightling CE, Kaur D, Berger $P$, et al. Differential expression of CCR3 and CXCR3 by human lung and bone marrow derived mast cells: implications for tissue mast cell migration. J Leukoc Biol 2005;77:759-66

11 Brightling CE, Ammit AJ, Kaur D, et al. The CXCL10/CXCR3 axis mediates human lung mast cell migration to asthmatic airway smooth muscle. Am J Respir Crit Care Med 2005;171:1103-8.

12 Miotto D, Christodoulopoulos P, Olivenstein R, et al. Expression of IFN- $\gamma$ inducible protein; monocyte chemotactic proteins 1, 3, and 4; and eotaxin in $\mathrm{T}(\mathrm{H}) 1$ - and $\mathrm{T}(\mathrm{H}) 2$-mediated lung diseases. J Allergy Clin Immunol 2001;107:664-70.

13 Bochner B, Hudson S, Xiao H, et al. Release of both CCR4-active and CXCR3active chemokines during human allergic pulmonary late-phase reactions. J Allergy Clin Immunol 2003;112:930-4.

14 Pilette C, Francis JN, Till SJ, et al. CCR4 ligands are up-regulated in the airways of atopic asthmatics after segmental allergen challenge. Eur Respir J 2004;23:876-84

15 Liu L, Jarjour NN, Busse WW, et al. Enhanced generation of helper T type 1 and 2 chemokines in allergen-induced asthma. Am J Respir Crit Care Med 2004; 169:1118-24.

16 O'Byrne PM, Inman MD, Adelroth E. Reassessing the Th2 cytokine basis of asthma. Trends Pharmacol Sci 2004;25:244-8.

17 Brightling CE, Symon FA, Birring SS, et al. TH2 cytokine expression in bronchoalveolar lavage fluid T lymphocytes and bronchial submucosa is a feature of asthma and eosinophilic bronchitis. J Allergy Clin Immunol 2002;110:899-905.

18 Berry MA, Parker D, Neale N, et al. Sputum and bronchial submucosal IL-13 expression in asthma and eosinophilic bronchitis. J Allergy Clin Immunol 2004; 114:1106-9.

19 Bradding P, Roberts JA, Britten KM, et al. Interleukin-4, -5 , and -6 and tumor necrosis factor-alpha in normal and asthmatic airways: evidence for the human mast cell as a source of these cytokines. Am J Respir Cell Mol Biol 1994; 10:471-80.

20 Broide DH, Paine MM, Firestein GS. Eosinophils express interleukin 5 and granulocyte macrophage-colony stimulating factor mRNA at sites of allergic inflammation in asthmatics. J Clin Invest 1992;90:1414-24.

21 Brightling CE, Symon FA, Holgate ST, et al. Interleukin-4 and - 13 expression is co-localized to mast cells within the airway smooth muscle in asthma. Clin Exp Allergy 2003;33:1711-6.

22 Sanmugalingam $D$, Wardlaw AJ, Bradding P. Adhesion of human lung mast cells to bronchial epithelium: evidence for a novel carbohydrate-mediated mechanism. J Leukoc Biol 2000;68:38-46.

23 Duffy SM, Leyland ML, Conley EC, et al. Voltage-dependent and calciumactivated ion channels in the human mast cell line HMC-1. J Leukoc Biol $2001 ; 70: 233-40$.

24 Olsson N, Rak S, Nilsson G. Demonstration of mast cell chemotactic activity in bronchoalveolar lavage fluid collected from asthmatic patients before and during pollen season. J Allergy Clin Immunol 2000;105:455-61.

25 Hirst SJ, Hallsworth MP, Peng Q, et al. Selective induction of eotaxin release by interleukin-13 or interleukin-4 in human airway smooth muscle cells is synergistic with interleukin- $1 \beta$ and is mediated by the interleukin- 4 receptor $\alpha$ chain. Am J Respir Crit Care Med 2002;165:1161-71.

26 Romagnani P, de Paulis A, Beltrame C, et al. Tryptase-chymase doublepositive human mast cells express the eotaxin receptor CCR3 and are attracted by CCR3-binding chemokines. Am J Pathol 1999;155:1195-204.

27 Nilsson G, Mikovits JA, Metcalfe DD, et al. Mast cell migratory response to interleukin-8 is mediated through interaction with chemokine receptor CXCR2/interleukin-8RB. Blood 1999:93:2791-7.

28 Loetscher P, Pellegrino A, Gong JH, et al. The ligands of CXC chemokine receptor 3, I-TAC, Mig, and IP10 are natural antagonists for CCR3. J Biol Chem 2001;276:2986-91.

29 Chambers LS, Black JL, Ge Q, et al. PAR-2 activation, PGE2, and COX-2 in human asthmatic and nonasthmatic airway smooth muscle cells. Am J Physiol Lung Cell Mol Physiol 2003;285:L619-27.

30 Burgess JK, Blake AE, Boustany S, et al. CD40 and OX40 ligands are increased on stimulated asthmatic airway smooth muscle. J Allergy Clin Immunol 2005; 1 15:302-8.

31 Tliba $\mathrm{O}$, Tliba S, Da Huang $C$, et al. Tumor necrosis factor $\alpha$ modulates airway smooth muscle function via the autocrine action of interferon $\beta$. J Biol Chem 2003;278:50615-23.

32 Ochi $H$, Hirani WM, Yuan Q, et al. Thelper cell type 2 cytokine-mediated comitogenic responses and CCR3 expression during differentiation of human mast cells in vitro. J Exp Med 1999;190:267-80.

\section{LUNG ALERT}

\section{A revised score for predicting $\mathrm{PE}$}

$\Delta$ Le Gal G, Righini M, Roy PM, et al. Prediction of pulmonary embolism in the emergency department: the revised Geneva score. Ann Intern Med 2006; 144:165-71

$\mathrm{C}$ linical variables were derived and validated in two independent cohorts of patients suspected of having a pulmonary embolism (PE). There were 965 patients in the derivation group and 756 in the validation group.

Univariate analysis identified 10 variables statistically associated with PE, eight of which remained significant in a multivariate analysis. Each variable was assigned points based on the regression coefficient: age $\geqslant 65$ years ( 1 point), previous deep venous thrombosis or PE ( 3 points), surgery or fracture within 1 month ( 2 points), active malignancy ( 2 points), unilateral lower limb pain ( 3 points), haemoptysis ( 2 points), heart rate $75-94 / \mathrm{min}$ ( 3 points) or $\geqslant 95 / \min$ ( 5 points), and pain on lower limb venous palpation with unilateral oedema (4 points). Using this revised score in the validation dataset, $8 \%$ of low probability patients ( $0-3$ points), $28 \%$ of independent probability patients (4-10 points), and $74 \%$ of high probability patients ( $\geqslant 11$ points) had PE. This system may therefore assist in identifying patients who can be safely left untreated and those who require invasive investigations.

This study improves on the original Geneva score as it is standardised, entirely clinical (not requiring assessment of arterial blood gases), and has internal and external validity. However, the clinical utility now needs to be addressed in a prospective study.

M Rajpopat

Royal Free Hospital, London, UK; m_rajpopat@hotmail.com 